\title{
IMPLANTAÇÃO DE COLETA SELETIVA EM ESCOLA DE ENSINO FUNDAMENTAL
}

\author{
Lilyanne Rocha Garcez - lilyannegarcez@gmail.com \\ Thays da Cruz Franco - thayscfranco@gmai.com \\ Antônio Bruno Guerra de Holanda Lima - brunoguerralima@ live.com \\ Faculdade de Tecnologia, Universidade Federal do Amazonas \\ Av. General Rodrigo Octavio Jordão Ramos, 1200 - Bairro: Coroado I \\ CEP 69067-005 - Manaus - Amazonas
}

\begin{abstract}
Hosana Emília Sarmento Costa Leite - hosanaemilia@ hotmail.com Instituto Federal de Educação, Ciência e Tecnologia de Pernambuco, Av. Prof. Luís Freire, 500 - Bairro: Cidade Universitária.

CEP 50.740-545 - Recife - Pernambuco
\end{abstract}

Resumo: Ações desenvolvidas durante a fase da Educação Escolar geralmente apresentam resultados satisfatórios considerando que o ser humano está em formação e consegue incutir valores e paradigmas que uma vez aprendidos, poderão ser levados para a vida toda. Diante desse aspecto considera-se de extrema relevância a execução de um plano de gerenciamento de resíduos sólidos com a implantação de coleta seletiva em ambiente um escolar de ensino fundamental. Nesse contexto, este trabalho resulta de uma atividade de extensão desenvolvida por docentes e estudantes do curso de engenharia civil, que teve como objetivo acompanhar a implantação da coleta seletiva em uma escola pública municipal de ensino fundamental I, na cidade de Manaus - Amazonas, atuando juntamente com gestores, funcionários e estudantes nas etapas do processo de coleta seletiva de forma lúdica e incentivando-os à reciclagem. Por ser um instrumento de transformação, a educação ambiental é essencial para a construção de uma consciência crítica sobre o meio ambiente. Destaca-se também que ensinar sobre coleta seletiva e segregação de resíduos às crianças de forma adequada gera benefícios que pode inclusive atingir o comportamento familiar destes pequenos atores quanto ao gerenciamento de seus resíduos dentro de casa.

Palavras-chave: Educação Ambiental. Atividade Lúdica. Coleta Seletiva. Extensão.

\section{INTRODUÇÃO}

A educação ambiental é um componente essencial da educação, devendo estar presente de forma articulada em todos os níveis e modalidades do processo educativo, pois tem papel fundamental em propiciar o aumento de conhecimento, mudança de valores, aperfeiçoamento de habilidades e contribuindo para estimular uma maior integração e harmonia dos indivíduos com o meio ambiente (BRASIL,1999; YAMAGUCHI et al., 2019).

Entre os diversos problemas mundiais contemporâneos que compõem a questão ambiental, a produção e descarte de resíduos sólidos de maneira adequada é um dos mais preocupantes sobre o qual, tanto pesquisadores como ambientalistas, têm dedicado horas de trabalho e significativos esforços científicos na busca de alternativas de solução. 
Para Lemos et al. (1999) abordar a problemática da falta de gerenciamento dos resíduos sólidos no processo de educação é um desafio, mas a educação formal é considerada como espaço privilegiado de transmissão de conhecimento, socialização do indivíduo, de formação de caráter e ruptura de paradigmas consolidados culturalmente na população sobre diversas questões do cotidiano. Assim, as formas utilizadas para proceder ao descarte e a destinação do de resíduo no processo de educação deve perpassar pela compreensão do indivíduo como parte atuante no meio em que vive, sendo o ser humano protagonista principal na construção do ambiente que o cerca, influenciando-o e sendo influenciado por ele.

Nesse contexto, coleta seletiva é o termo utilizado para o recolhimento dos materiais que são passíveis de serem reciclados, previamente separados na fonte geradora e contribui para a minimização de resíduos (REIS et al., 2020). Um sistema de coleta seletiva aborda a separação dos materiais com potencial de reciclagem, para posteriormente serem recolhidos por caminhões vinculados a órgãos públicos, empresas, entidades ou por catadores de materiais recicláveis, além de auxiliarem na implantação dos processos de reciclagem e cooperativas (SOUTO et al., 2013).

Segundo Simonetto e Borenstein (2004) a implantação da coleta seletiva é um processo contínuo que é ampliado gradativamente. O primeiro passo diz respeito à realização de campanhas informativas de conscientização junto à população, convencendo-a da importância da reciclagem e orientando-a para que separe os resíduos sólidos em recipientes adequados. Posteriormente, deve-se elaborar um plano de coleta, definindo equipamentos, veículos, áreas e a periodicidade de coleta. Finalmente, é necessária a instalação de unidades de triagem para limpeza e separação dos resíduos, organizando-os para a venda do material a ser reciclado.

Souza (2015) afirma que a implantação de um programa de coleta seletiva em escolas conduz professores e gestores a buscar fundamentos e desenvolver pesquisas na área, com o objetivo de preparar aulas e motivar estudantes às atividades propostas com a descoberta de um novo universo e a possibilidade de um trabalho homogêneo que possibilita a formação de cidadão críticos, capazes de agir de forma globalizada.

Assim, a necessidade de abordar a Educação Ambiental nas escolas se torna cada vez mais necessária, pois existem crianças e jovens que possuem interesse em relação a diversas variáveis ou até mesmo a preservação e conservação do meio em que vivem e nesse aspecto a educação ambiental pode estimular a prática de ações ecologicamente corretas para a obtenção de melhorias de uma sociedade. Reiterando que as ações podem consolidar o cotidiano, não somente no interior da instituição, mas também no exterior dela, pois pode promover a disseminação de ideias e a conscientização ambiental.

Diante desse cenário, o objetivo deste trabalho é apresentar o acompanhamento da implantação de coleta seletiva em uma escola municipal de ensino fundamental na cidade de Manaus, onde se obteve inicialmente dados referente a gestão dos resíduos e também se realizou jogos e brincadeiras de forma lúdica com os estudantes da escola, sendo uma atividade de extensão executada por docentes e dois graduandos do curso de engenharia civil.

\section{MATERIAIS E MÉTODOS}

$\mathrm{Na}$ etapa inicial de planejamento, foi imprescindível estabelecer a parceria com a gestão da escola para o desenvolvimento das atividades posteriores, analisar conjuntamente quanto a estrutura da escola para implantação da coleta seletiva e assim obter o apoio da gestão escolar e dos professores envolvidos.

Posterior a estes primeiros contatos, foram realizadas diversas visitas à escola para o levantamento de dados: número de atores (estudantes, professores, funcionários), quantidade 
diária do resíduo gerado (em peso ou número de sacos de lixo), quais tipos de resíduos e porcentagens de cada um (papel, alumínio, plástico, vidro, orgânicos etc.), o caminho percorrido pelo resíduo, desde onde é gerado até onde é acondicionado para a coleta, as instalações físicas (local para armazenagem), os recursos materiais existentes (tambores, latões e outros que poderiam ser reutilizados) e a rotina da limpeza (frequência, horários).

Para obtenção dos resultados necessários, foram aplicados aos funcionários da escola, tanto professores como técnicos, dois questionários, sendo um de múltipla escolha (Questionário 1) e outro para assinalar a concordância ao quesito (Questionário 2). Um terceiro questionário foi aplicado aos estudantes (Questionário 3). Ao total foram aplicados 54 (cinquenta e quatro) questionários aos funcionários e 94 (noventa e quatro) aos estudantes.

A partir dessas observações fez-se um estudo, em cooperação com os estudantes e funcionários, sobre as vantagens e desvantagens da coleta seletiva bem como as opções viáveis para encaminhar os materiais recicláveis à associações ou cooperativas.

Quadro 1 - Questionários aplicados

\begin{tabular}{|c|c|}
\hline $\begin{array}{l}\text { Questionário } 1 \text { aplicado aos funcionários das } \\
\text { escolas: }\end{array}$ & $\begin{array}{l}\text { Questionário } 2 \text { também aplicado aos funcionários } \\
\text { las escolas: }\end{array}$ \\
\hline $\begin{array}{l}\text { - O que você entende por educação ambiental? } \\
\text { - Processo de formação e informação orientado para } \\
\text { consciência sobre questões ambientais; } \\
\text { - É uma forma de educação que se aprende na escola; } \\
\text { - Discussão e aprendizagem de temas relacionados à } \\
\text { natureza. } \\
\text { - Que tipo de resíduo você considera o mais } \\
\text { produzido pela escola? } \\
\text { - Papel/papelão; } \\
\text { - Plástico; } \\
\text { - Têxteis sanitários; } \\
\text { - Vidro; } \\
\text { - Metal; }\end{array}$ & $\begin{array}{l}\text { a) Você consegue identificar coletores diferentes para } \\
\text { separação de resíduos na escola? (Sim ou não). } \\
\text { b)Os coletores existentes são utilizados de maneira } \\
\text { correta? (Sim ou não). } \\
\text { c) A escola possui algum tipo de programa educacional } \\
\text { acerca de resíduos sólidos? (Sim ou não). } \\
\text { d)A escola adota alguma metodologia para incentivar } \\
\text { a coleta seletiva? (Sim ou não). } \\
\text { e) Você sabe como funciona uma associação ou } \\
\text { cooperativa de catadores de recicláveis? (Sim ou não). } \\
\text { f) Você estaria disposto a modificar os procedimentos } \\
\text { atuais e adotar a coleta seletiva na escola? (Sim ou } \\
\text { não). }\end{array}$ \\
\hline $\begin{array}{l}\text { - Resíduos orgânicos; } \\
\text { - Outros (Eletrônicos, sintéticos etc.). }\end{array}$ & \\
\hline $\begin{array}{l}\text { - Qual fator mais dificulta a implantação de medidas } \\
\text { de educação ambiental? } \\
\text { - Vandalismo com os equipamentos de coleta } \\
\text { seletiva; } \\
\text { - Não comprometimento dos estudantes e } \\
\text { funcionários; } \\
\text { - Falta de apoio e participação dos órgãos públicos. } \\
\text { - Como conscientizar e comprometer os estudantes } \\
\text { sobre coleta seletiva? } \\
\text { - Palestras sobre a situação mundial e regional; } \\
\text { - Artigos de jornais e revistas; } \\
\text { - Campanhas publicitárias; } \\
\text { - Atividades dinâmicas e lúdicas. }\end{array}$ & $\begin{array}{l}\text { - Qual a sua idade? } \\
\text { - Qual seu ano escolar? } \\
\text { a) Você conhece as cores da coleta seletiva? (Sim ou } \\
\text { não). } \\
\text { b)Em sua casa, você separa o resíduo? (Sim ou não). } \\
\text { c) Sabe por que o resíduo deve ser separado antes de ir } \\
\text { para disposição final? (Sim ou não). } \\
\text { Você sabe para onde é destinado o resíduo da coleta } \\
\text { seletiva? (Sim ou não). }\end{array}$ \\
\hline
\end{tabular}

Fonte: Próprios autores

Na etapa de implantação foi necessário o auxílio dos gestores para a divisão da equipe de trabalho que dará continuidade ao programa, considerando ser um trabalho contínuo e, com uma equipe, se facilitará a realização e acompanhamento das tarefas. A equipe ou pessoa deverá ser responsável por várias ações, tais como: verificar os acondicionadores, as placas sinalizadoras, treinamento dos responsáveis pela coleta, eventos como uma exposição ou palestra referente ao tema, entre outros. 
A etapa de Educação Ambiental constitui um importante instrumento de mobilização da comunidade para a mudança de hábitos e atitudes que podem levar a sociedade a tomar medidas com ações que minimizem a quantidade de resíduos na própria fonte geradora. Integra todas as atividades de informação, sensibilização e mobilização de todos os envolvidos. Sendo assim, na escola todos os estudantes, professores, funcionários da área administrativa e da limpeza acompanharam as ações realizadas, como:

a) Criação de equipes para divisão de trabalho e execução eficiente;

b) Aplicação de questionários com funcionários e estudantes;

c) Compilação de dados obtidos por meio dos questionários;

d) Reuniões para manutenção do projeto, assim como destinação para o material coletado, por exemplo, cooperativas e associações;

e) Realização de atividades lúdicas educativas.

\section{RESULTADOS E DISCUSSÃO}

Entre os principais resultados encontrados, destaca-se primeiramente o estudo prévio das escolas e parcerias, bem como a elaboração e aplicação dos questionários. Quando questionados sobre a compreensão do tema "Educação Ambiental" unanimemente os funcionários entendem como um processo de formação e informação orientado para consciência sobre questões ambientais.

Quanto a percepção dos funcionários relativa ao tipo dos resíduos produzidos na escola, têm-se $67 \%$ para papel/papelão, 22\% para plásticos e $11 \%$ para resíduos orgânicos. É possível observar que pela percepção dos professores e técnicos, que os resíduos gerados em sala de aula ou ambientes administrativos comumente são os papeis, porém, no contexto escolar, os resíduos orgânicos também apresentam grande expressão e são provenientes principalmente da cantina da escola, copa e na produção da merenda escolar, como: o pó de café, restos de alimentos em sobras nos pratos, cascas e bagaço de frutas, verduras, legumes; cuja quantidade varia de acordo com o cardápio do dia.

Todo este resíduo orgânico transformado em compostagem serviria de adubo a ser utilizado nos jardins da própria escola ou até mesmo ajudar ser utilizado em hortas comunitárias dentro da própria escola. Essa atividade, além de integrar escola-comunidade, ajuda na produção de alimentos e poderia servir de base para auxiliar os professores das áreas biológicas na conscientização e manejo correto com a flora (SOUZA et al., 2020).

Vale destacar que a quantidade de papeis gerados em ambiente escolar também é expressivo e a reciclagem de papel oferece proteção e economia dos recursos naturais e ainda, possibilita promover a consciência para a redução do uso e reaproveitamento de papel, transformando-o em papel reciclado (GRIGOLETTO, 2012).

As Figuras 1 e 2 demonstram, respectivamente, a visão dos funcionários quanto ao fator que dificulta a implantação de medidas de educação ambiental e de como conscientizar e comprometer os estudantes sobre coleta seletiva.

Conforme Figura 1 é possível observar que há dificuldades para implantar um sistema de coleta seletiva. Para Reis et al. (2020) esse tema na educação deve ser tratado de forma ininterrupta, seja com ações simples como os projetos de coleta seletiva ou na implantação de programas mais criteriosos pelos professores em parceria com órgãos públicos.

Como expresso na Figura 2 as atividades lúdicas e dinâmicas foram apontadas como relevante para a o contexto da educação ambiental no ensino fundamental. Para Mouta et al. (2020) a utilização de recursos lúdicos na educação básica tem se tornado essencial para a construção do conhecimento, estimulando o aprendizado e a criatividade, desenvolvendo 
habilidades e competências necessárias para a vivência em comunidade, principalmente das crianças, por proporcionar condições para seu desenvolvimento físico, motor, emocional, cognitivo e social. Através do lúdico, as crianças desenvolvem importantes habilidades, como: atenção, memória, imitação, imaginação e também incrementam áreas da personalidade, afetividade, motricidade, inteligência, sociabilidade e criatividade.

Figura 1: Visão dos funcionários quanto as dificuldades de implantar ações de educação ambiental

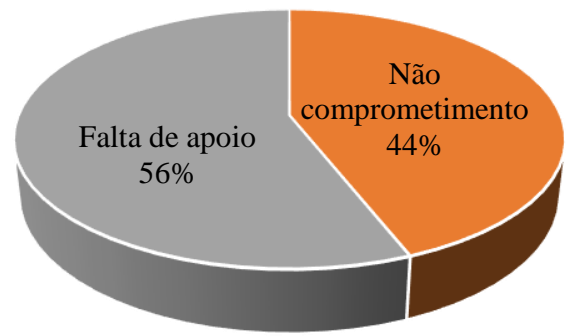

Fonte: próprios autores
Figura 2: Visão de como conscientizar os estudantes para a coleta seletiva

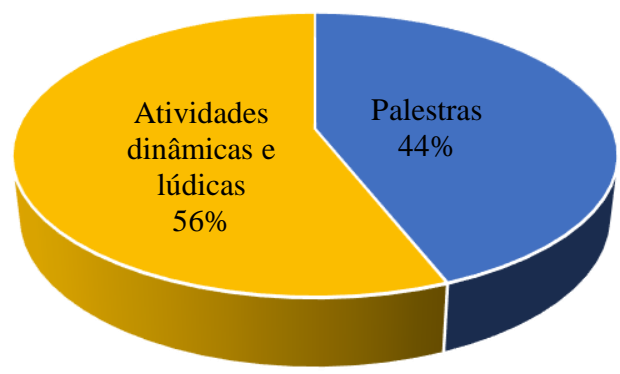

Fonte: próprios autores

A Figura 3 apresenta uma perspectiva dos funcionários quanto a positividade e negatividade dos quesitos elencados no Questionário 2.

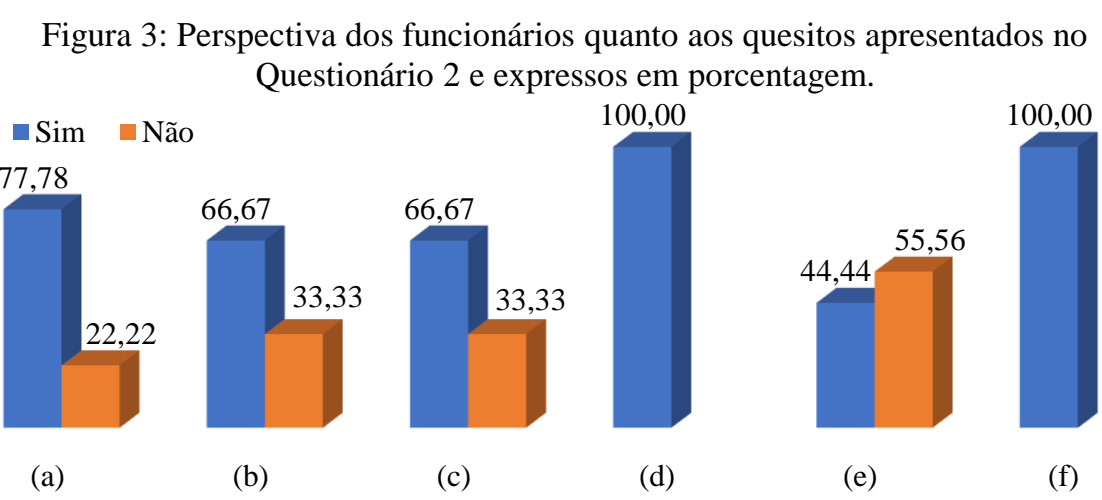

Fonte: próprios autores

É possível observar que a maioria dos entrevistados identificam os acondicionadores para a coleta seletiva (item a-77,78\%), bem como os utilizam de maneira correta (item b-66,67\%). Também vale destacar que a escola possui programa educacional acerca de resíduos sólidos (item c - 66,67\%) com o objetivo de cumprir com os requisitos apresentados na Agenda Ambiental Escolar que é um instrumento de planejamento participativo e democrático para o desenvolvimento sustentável de cada escola da cidade de Manaus (MANAUS, 2009).

Outro destaque apresentado pelos professores e técnicos é que a escola aborda metodologias para incentivar a coleta seletiva (item $d-100 \%$ ) e cada um está disposto continuar com as ações que envolvem a coleta seletiva (item $\mathrm{f}-100 \%$ ), mesmo que haja necessidade de algumas mudanças, haja vista a Educação Ambiental ser um processo de aprendizado contínuo, cotidiano, buscando a qualidade de vida e a preservação do ambiente, tornando a conscientização ambiental possível para a construção de um pensamento reflexivo sobre o uso dos recursos naturais (OLIVEIRA, et al., 2016).

Porém, foi assinalado que a maioria dos entrevistados (item e $-55,56 \%$ ) desconhecem o funcionamento de associação ou cooperativa de catadores, bem como a relevância deles no processo de coleta seletiva. Pereira e Teixeira (2011) afirmam que a função das cooperativas 
exerce uma função social importante à medida que proporciona a estruturação do trabalho dos catadores, ajuda na inserção desses atores perante a sociedade como profissionais e cidadãos, contribuindo também para minimizar o problema do desemprego nas cidades.

As Figuras 4 e 5 apresentam, em porcentagem, a quantidade de estudantes da Escola tendo como referência a idade e a classe escolar, respectivamente. É possível verificar que a maioria dos estudantes estão na faixa etária entre 6 a 9 (Figura 4) e a maioria estão no $3^{\circ}$ ou $4^{\circ}$ no ano escolar (Figura 5).

Figura 4: Porcentagem da quantidade de estudantes com base na idade

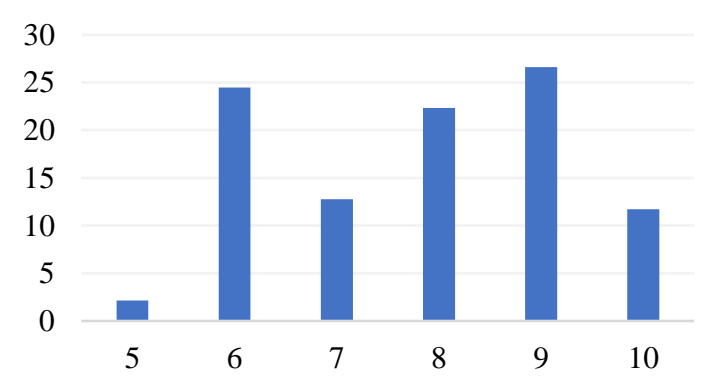

Fonte: próprios autores
Figura 5: Porcentagem da quantidade de estudantes com base na classe escolar

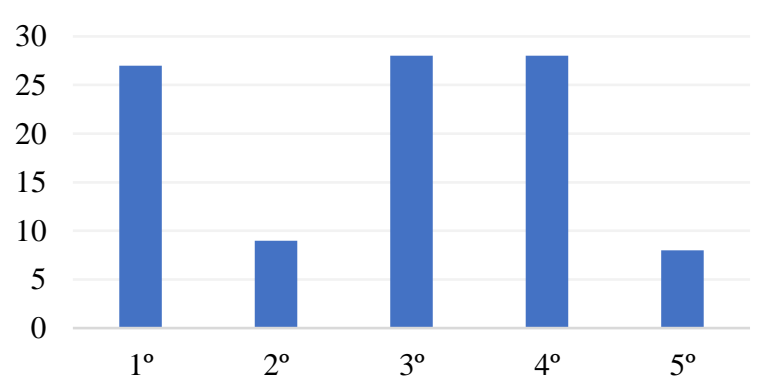

Fonte: próprios autores

A Figura 6 apresenta uma perspectiva dos estudantes quanto a positividade e negatividade dos quesitos elencados no Questionário 3 que se referem a coleta seletiva.

Figura 6: Percepção dos estudantes quanto a implantação da coleta seletiva, expressa em porcentgem.

— Sim $\square$ Não

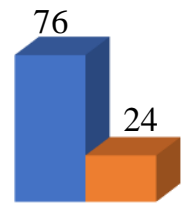

(a)

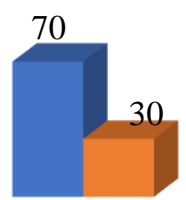

(b)

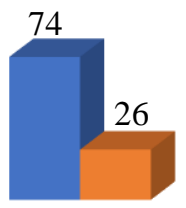

(c)

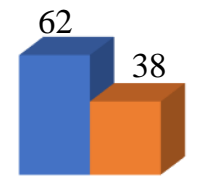

(d)

Fonte: próprios autores

Com base na Figura 6, destaca-se que as crianças já foram orientadas quanto as cores da coleta seletiva (item a), incentivadas a desenvolver essa separação em suas residências (item b), reconhecem a importância de separar os resíduos (item c) e sabem para onde são destinados após a separação e coleta (item d).

Souza et al. (2020) destaca que o ambiente escolar é um excelente lugar para se atuar com educação ambiental onde os professores contribuem para que o estudante tenha atitudes positivas e de práticas sustentáveis, incentivando o reuso e a reciclagem dos materiais utilizados dentro de sala de aula. Nesse contexto, implantar um sistema de coleta seletiva pode ser bastante didático, pois é possível inserir projetos que ensinem aos estudantes a elaboração de um sistema de compostagem, podem também elaborar e aplicar projetos de reciclagem, incentivar o descarte adequado dos resíduos e aliar o conhecimento que garanta a melhoria da qualidade do meio ambiente e da vida dentro e fora da escola.

Posterior a aplicação do questionário, foram efetuadas, para complementar os aspectos da educação ambiental, alguns jogos e brincadeiras com o intuito de fortalecer a implementação da coleta seletiva. Pinheiro e Cardoso (2020) mencionam que levar o lúdico para a sala de aula 
é uma alternativa plausível que pode ser usada pelos educadores como forma de despertar o interesse dos estudantes e motivá-los.

A Figura 7 apresenta a ideia de um jogo de dados, onde um dado é confeccionado pelas principais cores da coleta seletiva (Figura 7a) e deverá ser a assinalado ao chão trilhas onde as equipes caminharão conforme acertos de perguntas (Figura 7b).

Figura 7. a) Modelo de dado; b) trilha assinalada no chão

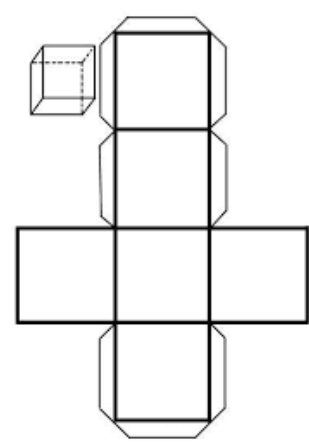

a)

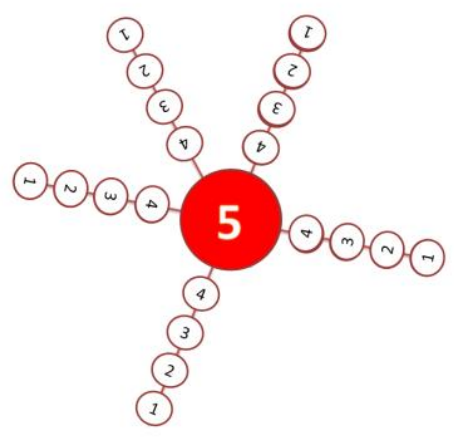

b)

Fonte: próprios autores

A quantidade mínima de participantes são cinco jogadores e como conteúdo deve-se obter o dado confeccionado com as cores azul, vermelho, verde, amarelo, marrom e laranja, identificando os acondicionadores, em papel/papelão, plástico, vidro, metal, orgânico e resíduo perigoso, respectivamente (Figura 7a). Além do dado deve-se marcar ao chão uma trilha conforme apresentado na Figura $7 \mathrm{~b}$. Deve-se elaborar 10 cards com perguntas de múltipla escolha de cada cor e 10 cards brancos com perguntas sem alternativas de respostas.

O jogo deve ser executado da seguinte maneira:

- Criar 5 equipes de jogadores;

- Posicionar um representante de cada equipe antes da marca número 1 de cada trilha;

- Um jogador da equipe deve rolar o dado;

- A cor tirada corresponde a um card, o professor deve fazer a pergunta referente à cor;

- A equipe deve ter um tempo para responder a pergunta;

- Em caso de acerto, a equipe avança uma casa e continua jogando;

- Em caso de erro, passar o dado para a próxima equipe;

- Quando a primeira equipe chegar no local marcado com o número 5, deve-se ler a pergunta de um card branco, que devem ser mais difíceis que as anteriores;

- Caso o jogador acerte, a equipe vence o jogo, em caso de erro, o jogo deve prosseguir os turnos até que alguma equipe acerte.

Outro jogo utilizado com as crianças foi o jogo de tabuleiro (Figura 8) com uso de peões e dado, elaborado e adaptado de Rangel e Miranda (2016). O jogo (Figura 8a) é formado por 65 casas, nas quais os peões passam de acordo com o número sorteado no dado jogado, 11 cartas sendo 5 relativas as casas do erro e 6 relativas a perguntas, que deverão ser respondidas pelo estudante. O jogo também apresenta as casas com perguntas que podem ser elaboradas a partir dos assuntos temáticos estudados em sala de aula (Figura 8b). Ao cair na casa das perguntas deve-se ler a questão correspondente e os quesitos com as respostas. Acertando a pergunta, o jogador avança casas. Ao errar, ele retorna. As chamadas casas do erro exemplificadas pelas Figuras $8 \mathrm{c}$ sinalizam algum erro que a pessoa possa cometer na sua vida cotidiana em relação ao lixo e reciclagem e sugere o retorno (por meio das cartas) em algumas casas, para reflexão do jogador. 
O jogo utilizado como instrumentação didática no processo de educação ambiental teve uma avaliação positiva na aceitação e satisfação dos estudantes, pois representou um instrumento motivador ao ensino de Educação Ambiental.

Figura 8: a) Tabuleiro do jogo Lixo e Reciclagem; b) Casa das interrogações/perguntas; d) Exemplos para as casas dos erros.
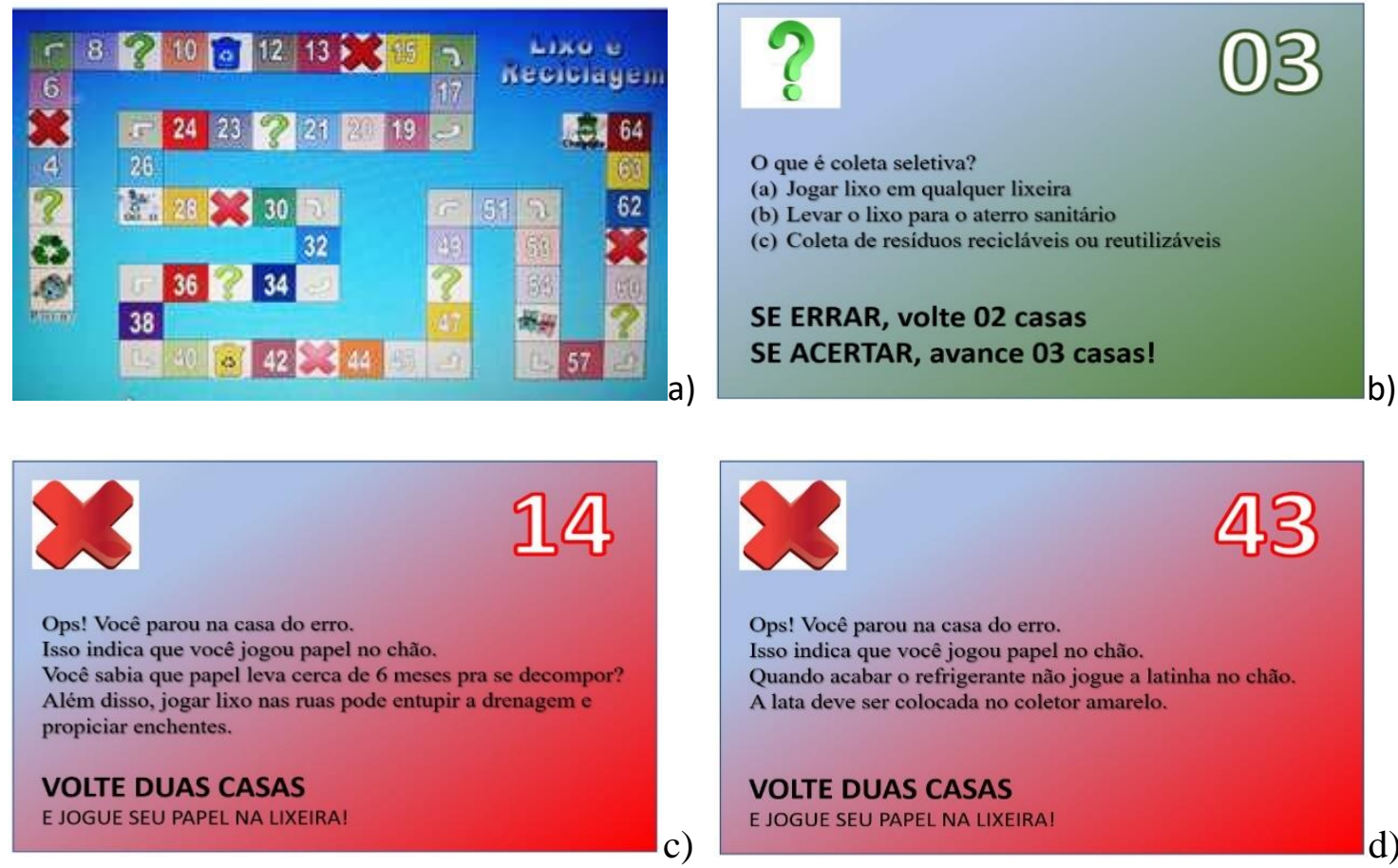

Fonte: próprios autores

Para Santos e Pereira (2019) a ludicidade na escola contribui com a promoção do saber, pois atua no desenvolvimento da criatividade, do raciocínio e da socialização. Na educação infantil permite uma adequada adaptação e consequentemente apropriação dos conhecimentos através do interesse e motivação, com isso, propicia o desenvolvimento cognitivo, social e cultural das crianças, com impactos preponderantes sobre o seu processo de ensinoaprendizagem e reflexos importantes sobre a vida escolar.

Também vale destacar que os jogos lúdicos no espaço escolar deriva na interação dos estudantes, no respeito entre o ganhador e o perdedor, resultando numa prática educativa e recreativa como instrumento educacional, desenvolvendo assim o raciocínio lógico, físico e mental. Se o estudante apresenta dificuldades na aprendizagem, os professores procuram novas práticas pedagógicas para melhor assimilação do conteúdo, e nestes casos, a ludicidade se faz presente como instrumento ativo fundamental no processo de desenvolvimento da criança (SANTOS et al., 2020). Ademais, uma apresentação lúdica nos meios de ensino torna o conhecimento mais inteligível para todas as idades e, principalmente, auxiliam no desenvolvimento infantil, em especial na atual sociedade progressivamente mais conectada nas plataformas virtuais, pois mantém a atenção seletiva das crianças (MOUTA et al., 2020).

\section{CONSIDERAÇÕES FINAIS}

Desenvolver atividades para incutir conhecimentos na criança durante a fase do ensino fundamental possui resultados satisfatórios já que é onde a criança se encontra em formação, apta a adquirir novas informações e aprimorar seus comportamentos para atitudes positivas que 
atingem o ambiente escolar e familiar. Portanto, a ideia de atuar nesta etapa da educação escolar executando o processo de coleta seletiva decorreu com êxito, pois foram elaboradas as fases e formas de implementação em conjunto com a gestão e professores, no qual os estudantes foram bastante participativos durante todo o processo.

Nesse contexto, reitera-se a relevância do gerenciamento de resíduos a todos os envolvidos, destacando que a implantação do programa de coleta seletiva aliado a ludicidade na educação ambiental motivou estudantes a desenvolver não somente as atividades propostas, mas também a uma reflexão para a sustentabilidade e a cidadania responsável.

Salienta-se que a escola já possui compreensão que a educação ambiental é um processo de formação e informação contínuo e o gerenciamento dos resíduos deve ser tratado de maneira ininterrupta. Nestes casos, as atividades lúdicas e dinâmicas foram apontadas como relevante no ambiente do ensino fundamental. Um ponto a destacar é o desconhecimento da atuação de associação ou cooperativa de catadores, nas proximidades da escola. Neste sentido considerase a ideia de buscar alguma associação que possa ministrar palestra mostrando o desenvolvimento e a relevância das atividades que eles executam para motivar a escola a contribuir com tais atividades.

Este projeto realçou como essencial a utilização de jogos como instrumentação didática no processo de educação, pois teve aceitação e satisfação dos estudantes e atuou como agente motivador na aprendizagem da educação ambiental. A ludicidade na escola permitiu que o conhecimento fosse introduzido a criança, estimulando sua criatividade, desenvolvendo o raciocínio e contribuindo para socialização junto aos outros colegas em classe.

\section{REFERENCIAS}

BRASIL. Lei n ${ }^{\circ}$ 9.795, de 27 de abril de 1999. Dispõe sobre a educação ambiental, institui a Política Nacional de Educação Ambiental e dá outras providências. Diário Oficial da União. Brasília, DF, 28 set. 1999.

\section{GRIGOLETTO, I.C.B. Reaproveitar e reciclar o papel: proposta de conscientização da preservação ambiental. Revista REMOA, p.1414-1422, 2012.}

LEMOS, J.C.; LIMA S.C.; ALVIM, N.M.C. Segregação de resíduos de serviços de saúde para reduzir os riscos à saúde pública e ao meio ambiente. Bioscience Journal. Uberlândia-MG: Universidade Federal de Uberlândia. 1999.

MANAUS, Agenda Ambiental Escolar. Secretaria Municipal de Educação. Departamento de Gestão Educacional. Acesso: a https://semed.manaus.am.gov.br/agenda-ambiental/ 2009.

MOUTA, A. A. N.; SILVA, N. S.; SOUZA, S. K. M. de; SILVA, A. C. B. da; COSTA, T. R. M.; SILVA, D. A.; SOUZA, R. I. M. B. de; OLIVEIRA, J. E. N.; LOPES, S. D. S.; BELTRÃO, R. P. L.. Saúde na escola: utilização do lúdico na educação básica para conscientização sobre a higienização pessoal e a prática da lavagem das mãos. Revista Eletrônica Acervo Saúde / Electronic Journal Collection Health. Vol.Sup.n.50. e3222. 2020.

OLIVEIRA, J. L. dos S.; SILVA, E. da; OLIVEIRA, H. M. de; SILVA, R. D. da; LIMA, J. R. de; SOUSA RÊGO, V. G. de. Gestão de resíduos sólidos em Patos, Paraíba: Um olhar sobre a coleta seletiva na escola e no comércio. Revista Espacios. V. 37, N 07. 2016.

PEREIRA, M. C. G. and TEIXEIRA, M. A. C.. A inclusão de catadores em programas de coleta seletiva: da agenda local à nacional. Cad. EBAPE.BR. V.9, n.3, pp.895-913, 2011.

PINHEIRO, A. R. \& CARDOSO, S. P.. O lúdico no ensino de ciências: uma revisão na Revista Brasileira de Pesquisa em Educação em Ciências. Revista Insignare Scientia. Vol. 3, n. 1. 2020. 
RANGEL, T. R. \& MIRANDA, A. C. de. Atividade lúdica como inserção da Educação Ambiental no Ensino Fundamental. Revista Educação Ambiental em ação. Número 55, Ano XIV. MarçoMaio/2016.

REIS, D. da S.; OLIVEIRA, L. M. de; GONÇALVES, M. C. da S.. A Educação e o Meio Ambiente na Perspectiva da Agenda 2030: pesquisa participante sobre coleta seletiva no ambiente escolar. Educação In Loco, V.01, n.1. 2020.

SANTOS, A. A. \& PEREIRA, O. J.. A importância dos jogos e brincadeiras lúdicas na Educação Infantil. Revista Eletrônica Pesquiseduca. Santos, Volume 11, número 25, p. 480-493. 2019.

SANTOS, C. dos; SANTOS, D. P. dos; LIMA, M. A. de. A Importância da Atividade Lúdica na Educação Matemática. Revista Psicologia \& Saberes. v. 9, n. 14, 2020.

SIMONETTO, E. de O. \& BORENSTEIN, D.. Sistema de Apoio à Decisão Aplicado ao Planejamento e Distribuição da Coleta Seletiva de Resíduos Sólidos. XXIV Encontro Nac. de Eng. de Produção - Florianópolis. ENEGEP 2004.

SOUTO, F. B. D.; RAIMAM, M. P.; ALBINO, U. B.. Resíduos Sólidos Urbanos em Porto de Moz - PA: Problemas e Oportunidades. Rev. Geogr. Acadêmica v.7, n.2, pág 85-94. 2013.

SOUZA, R. A. Coleta Seletiva escolar: o reaproveitamento de Resíduos Sólidos no ambiente escolar. Dissertação de Mestrado. Unicastelo. 2015.

SOUZA, R. B. B.; SILVA FILHO, A. J.; SOUZA, R. B.. Caracterização de resíduos sólidos em uma escola pública estadual no município de Barreiras/Bahia. Nature and Conservation, v.13, n.1, p.43-49, 2020.

YAMAGUCHI, H. K. de L.; ANDRADE, A. B. de; SOUZA, F. F.; ALHO, J. M.. Brincando e Conhecendo os Peixes da Amazônia: Uma Ferramenta Lúdica para Percepção Ambiental na Educação Infantil. Nexus - Revista de Extensão. № 9, Ano 5, Dez. 2019.

\title{
IMPLEMENTATION OF SELECTIVE COLLECTION IN FUNDAMENTAL EDUCATION SCHOOL
}

\begin{abstract}
Actions developed during the School Education phase generally present satisfactory results considering that the human being is in training and manages to instill values and paradigms that, once learned, can be taken for life. In view of this aspect, the execution of a solid waste management plan with the implementation of selective collection in an elementary school environment is considered extremely relevant. In this context, this work results from an extension activity that aimed to accompany the implementation of selective collection in a municipal public school of elementary education, in the city of Manaus - Amazonas, working together with managers, employees and students in the stages of the process selective collection in a playful way and encouraging recycling. As an instrument of transformation, environmental education is essential for building a critical awareness of the environment. It is also noteworthy that teaching children about selective collection and segregation of waste in an appropriate manner generates benefits that can even reach the family behavior of these small actors regarding the management of their waste at home.
\end{abstract}

Keywords: Environmental Education. Playful activity. Selective collect. Extension. 